\title{
Neuropathological features of genetically confirmed DYT1 dystonia: investigating disease- specific inclusions
}

\author{
Reema Paudel ${ }^{1}$, Aoife Kiely ${ }^{2}$, Abi Li ${ }^{2}$, Tammaryn Lashley², Rina Bandopadhyay², John Hardy ${ }^{2}$, Hyder A Jinnah³, \\ Kailash Bhatia ${ }^{1}$, Henry Houlden ${ }^{1}$ and Janice L Holton ${ }^{1,2^{*}}$
}

\begin{abstract}
Introduction: Early onset isolated dystonia (DYT1) is linked to a three base pair deletion ( $\triangle G A G$ ) mutation in the TOR1A gene. Clinical manifestation includes intermittent muscle contraction leading to twisting movements or abnormal postures. Neuropathological studies on DYT1 cases are limited, most showing no significant abnormalities. In one study, brainstem intraneuronal inclusions immunoreactive for ubiquitin, torsinA and lamin A/C were described. Using the largest series reported to date comprising 7 DYT1 cases, we aimed to identify consistent neuropathological features in the disease and determine whether we would find the same intraneuronal inclusions as previously reported.
\end{abstract}

Result: The pathological changes of brainstem inclusions reported in DYT1 dystonia were not replicated in our case series. Other anatomical regions implicated in dystonia showed no disease-specific pathological intracellular inclusions or evidence of more than mild neuronal loss.

Conclusion: Our findings suggest that the intracellular inclusions described previously in DYT1 dystonia may not be a hallmark feature of the disorder. In isolated dystonia, DYT1 in particular, biochemical changes may be more relevant than the morphological changes.

Keywords: DYT1, Neuropathology, Isolated dystonia, Inclusions

\section{Introduction}

Dystonia is a common and heterogeneous neurological disorder. Recently, dystonia has been defined as a movement disorder characterized by sustained or intermittent muscle contractions causing abnormal, often repetitive, movements, postures, or both with genetic heterogeneity reported. The term 'dystonia musculorum deformans' was proposed in 1911 to describe a disorder in children with twisted postures, muscle spasms, gait abnormalities and clonic, rhythmic jerking movements [1]. In childhood onset cases dystonia tends to become generalized, while remaining focal or segmental in adult onset cases [2]. A newly proposed classification system classified dystonia according to two axes: clinical characteristics and etiology

\footnotetext{
* Correspondence: janice.holton@ucl.ac.uk

'Department of Molecular Neuroscience, UCL Institute of Neurology, London, UK

${ }^{2}$ Queen Square Brain Bank, UCL Institute of Neurology, London, UK

Full list of author information is available at the end of the article
}

[3]. Dystonia linked to a 3 base pair deletion ( $\triangle$ GAG) mutation in exon 5 of the TOR1A gene on chromosome 9q34.11 is called DYT1 dystonia [4]. The new classification system classified DYT1 dystonia as isolated dystonia in which dystonia is the only clinical sign with the exception of tremor [3]. The prevalence of isolated dystonia was estimated at 330 per million in Rochester, Minnesota [5] and is about 152 per million in the European population [6]. In DYT1 the inheritance is autosomal dominant with the disease onset in childhood [7] and the most common clinical features include muscle contractions affecting the leg or arm, often progressing to generalized involvement with severe disability [8]. The mutation has been identified in many diverse ethnic groups $[9,10]$ and has a low penetrance of 30-40\% [10-12].

The TOR1A gene encodes a 332 amino acid protein, torsinA, which has a cytoplasmic localization in cells. Torsin A is widely expressed throughout the central 
nervous system in humans, but is found at particularly high levels in dopaminergic neurons of the substantia nigra, locus coeruleus, Purkinje cells, cerebellar dentate nucleus, basis pontis, thalamus, hippocampal formation, oculomotor nuclei and frontal cortex [13-16]. The exact function of torsinA remains unclear in humans. However, mutant torsinA protein has been shown to have aberrant cellular localization and impaired protein interactions and is associated with defective synaptic vesicle formation and altered development of neuronal pathways [17].

Much of the research in primary dystonia has focused on the role of the basal ganglia in disease [18-20]. However, imaging studies of patients carrying a mutation in TOR1A causing primary dystonia revealed an increase in metabolic brain activity not only in the basal ganglia but also in the cerebellum $[21,22]$. Neuropathological investigation of clinically diagnosed primary dystonia cases has been generally disappointing with no specific abnormalities observed [23]. In genetically confirmed DYT1 cases, no evidence of neuronal loss, inflammation or altered localization of torsin A could be identified [15,23-26]. A possible reduction in striatal dopamine and the size of pigmented neurons in the substantia nigra have been suggested $[15,23,26]$. The most interesting observation to date has been the finding of perinuclear intraneuronal inclusions immunoreactive for ubiquitin, torsin A and lamin $\mathrm{A} / \mathrm{C}$ in the periaqueductal grey matter, cuneiform and pedunculopontine nuclei [27]. Similar inclusions were reported in some of the DYT1 mouse models produced by expression of transgenic human torsinA but this has not been a consistent finding $[28,29]$. The intriguing observation of brainstem inclusions in DYT1 cases has not, so far, been replicated.

The aims of this current study were: 1) to report the neuropathological features of seven previously unreported genetically proven DYT1 cases, 2) to determine whether any pathological features were consistently observed in all cases and could be regarded as disease-related and 3) to determine whether the perinuclear intracytoplasmic inclusions previously described in DYT1 dystonia are a consistent feature of the disease.

\section{Materials and methods \\ Cases}

This project was approved by the Joint Local Research Ethics Committee of the National Hospital for Neurology and Neurosurgery and the UCL Institute of Neurology. Autopsy specimens of 7 DYT1 confirmed cases were received from the Brain and Tissue Banks for Developmental Disorders, Baltimore. Clinical details, macroscopic findings and neuropathology reports were provided by the institution. To our knowledge, none of the DYT1 cases have been previously reported. Formalin fixed, paraffin embedded brain tissue was available in all dystonia cases although systematic sampling of multiple regions for each case was not possible due to the retrospective nature of the study. Where possible the frontal and temporal cortices, striatum, globus pallidus, thalamus, subthalamic nucleus, cerebellum, midbrain, pons, and medulla were investigated. Brain regions available for study in each case are indicated in Additional file 1: Table S1. The midbrain was absent in cases 2 and 3 and was only partially represented in case 6 . The pons including the reticular formation was present in all cases except case 6 .

\section{Genetics}

DNA was extracted from frozen brain tissue (cerebellum or frontal cortex) using DNeasy Blood and Tissue Kit (Cat no 69504). Cases were sequenced for the recurring $\triangle$ GAG mutation in exon 5 of TOR1A using standard Sanger polymerase chain reaction sequencing on an ABI 3730XL machine (Applied Biosystems, Inc., Foster City, CA, USA) and analyzed using Sequencher software.

\section{Immunohistochemistry (IHC)}

In brief, paraffin embedded tissue sections $(7 \mu \mathrm{m})$ were cut and stained using routine methods, including hematoxylin and eosin, Gallyas silver and Luxol fast blue/cresyl violet. IHC staining was performed according to a standard avidin-biotin complex protocol using the following antibodies: ubiquitin (1:200, Dako, Ely,UK), tau (1:600, AT8, Autogen Bioclear, Calne, UK); AT100 (1:200, Innogenetics, Gent, Belgium), glial fibrillary acidic protein (GFAP; 1:1,000, Dako), A $\beta$ (1:200, Dako), $\alpha$-synuclein (1:50, Novacastra, Newcastle, UK), $\alpha$-synuclein $(1: 1000, B D$ Transduction Biolabs, Oxford, UK), p62 (1:100, BD Bioscience, Oxford, UK), CD68 (1:150, Dako), and TDP-43 (1:2000, Protein Tech, Manchester, UK). Antibodies to ubiquitin, p62, and tau required pretreatment by pressure cooking in sodium citrate buffer, $\mathrm{pH}$ 6.0, for 10 minutes before IHC staining. Sections to be used for IHC staining with antibodies to $\alpha$-synuclein and $A \beta$ were treated with formic acid for 30 minutes before pressure cooking as described above. For GFAP IHC, pre-treatment with proteinase $\mathrm{K}$ was used. Antibody binding sites were visualized using the chromogen diaminobenzidine, and sections were counterstained using Mayer's hematoxylin.

\section{Neuropathology assessment}

The staining protocol was designed to detect intracellular inclusions as previously described in DYT1 dystonia [27]. In all cases brain regions including the midbrain and pons were stained with antibodies to ubiquitin and p62 to assess the presence of intraneuronal inclusions [27]. Due to limited tissue availability the periaqueductal grey matter was not available in all cases (absent in cases 2, 3 and 6). The pontine tegmentum was available in all cases except case 6. Cases were systematically screened for additional 
neuropathological changes. Using $A \beta$ IHC vascular and parenchymal $A \beta$ deposition was determined in the frontal cortex and diffuse and mature plaque load was assessed based on the criteria of the Consortium to Establish a Registry for Alzheimer's Disease (CERAD) [30]. Neurofibrillary tangle (NFT) pathology was determined using tau IHC and staged where possible according to the method of Braak and Braak [31]. Vascular pathology was assessed and tau, ubiquitin, and $\alpha$-synuclein IHC were performed in selected regions to exclude progressive supranuclear palsy, corticobasal degeneration, Parkinson disease and multiple system atrophy as described previously [32]. Where brainstem Lewy bodies (LBs) were identified cortical LB pathology was also determined [33].

\section{Results}

\section{Genetics}

Sanger sequencing confirmed that all the cases harbour the $\triangle$ GAG mutation (p.303-/Glu304) in exon 5 of the TOR1A gene which is a recurring mutation in DYT1 dystonia.

\section{Clinical data}

The demographic and clinical data for the cases are summarized in Table 1.

Case 1: This Caucasian female ( $\triangle$ GAG mutation carrier) was 89 years old at death. Despite having a strong family history of dystonia she was clinically unaffected. Her grandson had torticollis. Her sister (case 2) and niece were positive for the $\triangle$ GAG mutation. She had a medical history of hypertension, coronary artery disease, arterial vascular insufficiency involving left arm and developed cognitive impairment.

Case 2: A Caucasian woman ( $\triangle$ GAG mutation carrier) who died at the age of 87 years had a past medical history of hypertension, hyperlipidemia, coronary artery disease, pulmonary embolism, hypothyroidism, osteoarthritis and dementia. Although unaffected herself, she had a family history of dystonia. Her sister (case 1) and niece were both positive for $\triangle$ GAG mutation. She died following a right middle cerebral artery infarction confirmed prior to death by imaging studies.
Case 3: This Caucasian female, positive for $\triangle$ GAG mutation, had a clinical diagnosis of dystonia with life-long disability. Dystonic symptoms started at the age of 9 or 10 and were slowly progressive. She had a similarly affected sibling but no other family history was available. By 73 years of age she was weak bilaterally in the upper and lower limbs and wheelchair bound. Abnormal involuntary movements affected both upper extremities. She complained of progressive bilateral hearing loss and episodic problems with her vision and speech. Neurological examination reported no facial asymmetry, weakness in the both upper and both lower extremities, more severe proximally than distally. Deep tendon reflexes were diminished in the upper extremities, but symmetrical. Sensory evaluation showed intact pinprick and vibration sensation in both hands and right foot but these were absent in the left leg. No obvious cerebellar dysfunction was reported. She died at the age of 77 .

Case 4: A Caucasian female ( $\triangle$ GAG mutation carrier) of Jewish ancestry died at the age of 90 years. She had been well until the age of 89 when she developed left sided weakness, expressive aphasia and dysphagia secondary to stroke. She also had intermittent confusion and paranoia. MRI reportedly showed an infarct involving the right internal capsule, thalamus and white matter. She did not have a history of movement disorder; however, her grandson had a diagnosis of dystonia.

Case 5: A Caucasian female with a clinical diagnosis of dystonia died at the age of 90 years. Her son had a confirmed $\triangle$ GAG mutation. No further medical history was available.

Case 6: This Caucasian female was a $\triangle$ GAG mutation carrier and died aged 88 years. No further medical history was available.

Case 7: This Caucasian male ( $\triangle$ GAG mutation carrier) was unaffected by dystonia and died at the age of 75 . No further clinical history was available.

\section{Neuropathology assessment}

A summary of the pathological findings is given in Table 2.

\section{Table 1 Demographics and clinical details of DYT1 cases}

\begin{tabular}{|c|c|c|c|c|c|c|c|}
\hline Case & Sex & Ethnicity & Phenotype & Family history & Age at onset, years & Age at death, years & Cause of death \\
\hline 1 & $F$ & American Caucasian & Non-manifesting & + & $\mathrm{N} / \mathrm{A}$ & 89 & Natural \\
\hline 2 & $\mathrm{~F}$ & American Caucasian & Non-manifesting & + & N/A & 87 & Stroke \\
\hline 3 & $F$ & American Caucasian & Affected & - & $\sim 9-10$ & 77 & Complications of disorder \\
\hline 4 & $\mathrm{~F}$ & American Caucasian & Non-manifesting & + & $\mathrm{N} / \mathrm{A}$ & 90 & Stroke \\
\hline 5 & $\mathrm{~F}$ & American Caucasian & Affected & + & $\mathrm{N} / \mathrm{A}$ & 90 & Natural \\
\hline 6 & $\mathrm{~F}$ & American Caucasian & Non-manifesting & $\mathrm{N} / \mathrm{A}$ & $\mathrm{N} / \mathrm{A}$ & 88 & $\mathrm{~N} / \mathrm{A}$ \\
\hline 7 & M & American Caucasian & Non-manifesting & $\mathrm{N} / \mathrm{A}$ & N/A & 75 & Natural \\
\hline
\end{tabular}


Table 2 Summary of pathological findings in DYT1 cases

\begin{tabular}{|c|c|c|c|c|c|c|c|c|c|}
\hline \multirow[t]{2}{*}{ Case } & \multirow{2}{*}{$\begin{array}{l}\text { Brain } \\
\text { weight }(g)^{*}\end{array}$} & \multirow[t]{2}{*}{ Infarction } & \multicolumn{2}{|c|}{ Aß pathology } & \multirow[t]{2}{*}{ Tau pathology } & \multirow[t]{2}{*}{ Lewy body pathology } & \multirow[t]{2}{*}{ SVD } & \multirow[t]{2}{*}{ CAA } & \multirow[t]{2}{*}{ Final neuropathological diagnosis* } \\
\hline & & & $D$ & $M$ & & & & & \\
\hline \multirow[t]{5}{*}{1} & N/A & - & + & - & - & - & + & - & - moderate atherosclerosis of cerebral vessels \\
\hline & & & & & & & & & $\begin{array}{l}\text { - mild neuronal loss and gliosis in hippocampus } \\
\text { between the CA1 region and the subiculum }\end{array}$ \\
\hline & & & & & & & & & • mild loss of Purkinje cells in the cerebellum \\
\hline & & & & & & & & & - mineralization of vessel walls in the dentate nucleus \\
\hline & & & & & & & & & - non-specific neurodegenerative changes \\
\hline \multirow[t]{3}{*}{2} & 1110 & globus pallidus & + & + & - & - & +++ & + & - mild cerebral artery atherosclerosis \\
\hline & & & & & & & & & - right middle cerebral artery territory subacute infarct \\
\hline & & & & & & & & & - possible AD \\
\hline \multirow[t]{3}{*}{3} & 1200 & - & - & - & - & - & - & - & - mild cortical atrophy \\
\hline & & & & & & & & & - small areas of infarction \\
\hline & & & & & & & & & $\begin{array}{l}\text { - cerebral athero-arterio-arteriolosclerosis, remote } \\
\text { frontal white matter infarct }\end{array}$ \\
\hline \multirow[t]{2}{*}{4} & 1010 & globus pallidus & +++ & ++ & + (cortex, striatum and brainstem) & - & + & ++ & $\begin{array}{l}\text { - cerebral artho-arteriosclerosis (a) microinfarcts in } \\
\text { cerebral white matter, deep gray nuclei and } \\
\text { occipital cortex (b) macro infarct in right posterior } \\
\text { internal capsule and pulvinar }\end{array}$ \\
\hline & & & & & & & & & • hippocampal sclerosis \\
\hline \multirow[t]{2}{*}{5} & N/A & midbrain tegmentum & ++ & ++ & + (cortex, striatum and brainstem) & ++ (cortical and brainstem) & + & - & $\begin{array}{l}\text { - diffuse } L B \text { disease (a) substantia nigra degeneration } \\
\text { with LBs (b) neocortical LBs (c) AD neuropathology }\end{array}$ \\
\hline & & & & & & & & & $\begin{array}{l}\text { - cerebrovascular disease (a)numerous infartcs of } \\
\text { different ages (b) atherosclerotic disease of circle } \\
\text { of Willis arteries }\end{array}$ \\
\hline \multirow[t]{2}{*}{6} & 1184 & - & ++ & + & + (cortex, striatum and brainstem) & - & + & + & - brain generalized atrophy \\
\hline & & & & & & & & & - focal acute (perimortem) petechial hemorrhages \\
\hline 7 & N/A & - & - & - & + (brainstem) & + (substantia nigra) & - & - & $\begin{array}{l}\text { - melanocytic neoplasm with diffuse leptomeningeal } \\
\text { and perineural spread }\end{array}$ \\
\hline
\end{tabular}

$-=$ absent; += occasional/mild; ++= moderate; +++= severe; N/A-not available; SVD- Small vessel disease; CAA- Cerebral amyloid angiopathy; Aß: D-diffuse plaques, M-mature plaques; AD: Alzheimer's disease; LB: Lewy body; *: Derived from neuropathology report issued by BTDBB. 


\section{Macroscopic findings}

The macroscopic details were available from the neuropathology reports supplied by the brain bank providing the case. In all the DYT1 cases the weight of the unfixed brains was in the normal range [34] or mildly reduced (range 1010 - $1200 \mathrm{~g}$, data available for cases 2-4 and 6). The blood vessels of the circle of Willis showed variable atherosclerosis in all cases except case 7. Mild cerebral cortical atrophy was evident in case 3 and generalized brain atrophy consistent with age was described in case 6. At brain slicing the cortical ribbon was well preserved in all cases. The ventricular system was unremarkable in cases 3 and 4 but there was moderate dilatation in case 2 . Four cases showed cerebral infarction, this affected the right middle cerebral artery territory in case 2, frontal white matter in case 3 , several infarcts of varying age with unspecified distribution in case 5 , and multiple regions of cerebral white matter, occipital cortex and deep grey nuclei in case 4 . Case 7 was found to have a diffuse leptomeningeal melanocytoma. Pigmentation of the substantia nigra and locus coeruleus was described in cases 2 , 3,4 , and 6 where it was noted to be normal.

\section{Histological findings}

Examination of the midbrain and pons, represented in all cases except cases 6, using ubiquitin and p62 IHC showed no evidence of NCIs of similar distribution and morphology to those previously associated with early-onset DYT1 dystonia [27]. Moreover a detailed examination of additional brain regions did not reveal similar inclusions in other structures.

DYT1 cases were systematically assessed for other neuropathological abnormalities. Neuronal loss was generally inconspicuous in the regions studied. There was mild neuronal cell loss in the pigmented neurons of the substantia nigra pars compacta of case 1, 4, 5 and 7 and in the locus coeruleus of case 2, 4 and 5. Mild to moderate Purkinje cell loss was observed in the cerebellum of all the cases. Mild to moderate gliosis of the striatum was observed in all the cases and also in the substantia nigra of cases 1, 4 5, 6 and 7 in which it was available for analysis. The pontine base showed variable gliosis and this was severe in case 3. Vascular pathology and ischemic damage in the form of small vessel disease (SVD), cerebral amyloid angiopathy (CAA) and infarction was assessed in all cases. Cases 1, 4, 5 and 6 had mild SVD while this was severe in case 2. CAA was mild in cases 2 and 6 and moderate in case 4 . Small areas of infarction were observed in 3 cases. In cases 2 and 4 infarcts involved the globus pallidus and in case 5 a small infarct was noted in the midbrain tegmentum. We used two different $\alpha$-synuclein antibodies for IHC in multiple regions to assess LB pathology. LBs were observed in case 5 and rare LBs were observed in the substantia nigra of case 7 . Sparse diffuse $A \beta$ plaques were noted in the cortex of case 1 . In cases 2, 4, 5 and 6 both diffuse and mature cortical $A \beta$ plaques were present. Tau pathology in the form of NFTs and neuropil threads was evident in four cases (cases 4, 5, 6 and 7).

No consistent abnormalities were noted in the brain regions available for examination in this study including the midbrain, striatum, globus pallidus, cerebellum, and pons. Apart from limited Alzheimer's and LB pathology as described above, none of the cases were found to have neuropathological features of any other neurodegenerative disease. In particular, multiple system atrophy, progressive supranuclear palsy and corticobasal degeneration were excluded.

Additional file 1: Table S1 summarizes the semiquantitative findings of the histological features of the seven DYT1 cases.

\section{Discussion}

There are only five neuropathological studies of genetically confirmed DYT1 mutation cases in the literature [23]. We aimed to significantly contribute to the field of dystonia research by assessing the largest case series of DYT1 yet investigated to determine whether consistent neuropathological features could be identified as a hallmark of the disease. This study also addressed the question of whether neuronal perinuclear intracytoplasmic inclusions of the type previously associated with early-onset DYT1 dystonia could be confirmed in our cases [27].

We confirmed that all of the cases carry a 3-basepair deletion $(\triangle \mathrm{GAG})$ in exon 5 of the TOR1A gene which is a common mutation in DYT1 dystonia. Among the seven cases studied, two cases (cases 3 and 5) were symptomatic and five were asymptomatic carriers for DYT1 dystonia (cases 1, 2, 4, 6, and 7). Using a similar IHC approach to that applied in a previous neuropathological study of DYT1 dystonia [27] we did not replicate the finding of ubiquitin positive inclusions in the midbrain and pons with the exception of inclusions that were also immunoreactive for tau or $\alpha$-synuclein, representing NFTs and LBs respectively. We also screened for intracellular inclusions in other brain regions and could not demonstrate abnormality other than sparse Alzheimer and LB pathology. The remaining pathological features identified in the cases were those of gliosis, mild-moderate Purkinje cell depletion, CAA, SVD of varying severity and cerebral infarcts. None of these changes can be regarded as disease specific and are most likely to be due to the advanced age at death of the cases (75-90 years).

We examined anatomical regions implicated in dystonia and found no pathological intracellular inclusions or evidence of more than mild neuronal loss in the caudate, putamen, subthalamic nucleus, thalamus, pigmented neurons of the substantia nigra and globus pallidus, other 
than that associated with small infarcts in the latter in two cases [35].

The reason that we failed to replicate the findings of McNaught et al. [27] is uncertain. With the exception of case 4 in the McNaught series, who was aged 33 years at death, the ages of our 2 case series were similar excluding the possibility that the inclusions observed are age related. One difference between the two studies is that all four cases described by McNaught et al. manifested clinical dystonia compared with only two cases in our series, the remaining five cases that we investigated were non-manifesting carriers of the gene mutation. If the neuronal inclusions are only present in patients with clinical dystonia this may have reduced the likelihood that we would have detected inclusions in our cases. However, similar electrophysiological and functional imaging abnormalities have been reported in cortical motor circuits of manifesting and non-manifesting DYT1 carriers [36,37]. An alternative explanation could be that different antibodies were used in the two studies and this remains a possibility. Given the limitation that only a small amount of tissue was available for study we chose ubiquitin and p62 as screening antibodies as they target abnormally folded proteins for degradation by the proteasome and autophagy respectively. As both are sensitive markers of inclusions formed from a wide variety of different proteins in neurodegenerative diseases and can recognise proteinaceous inclusions for which the principle protein component has not been identified we argued that if DYT1 dystonia is associated with intraneuronal inclusions these would be highlighted by one or both of these antibodies $[38,39]$. Any inclusions identified could then have been further defined using other specific antibodies such as lamin $\mathrm{A} / \mathrm{C}$ or torsin $\mathrm{A}$ and the affected neurons would have been immunophenotyped to determine whether cholinergic neurons were affected as described in the McNaught study. A limitation of our study was that, due to the restricted tissue available for examination, not all regions were present in each case. It therefore remains a possibility that because of these sampling issues we did not identify rare inclusions. Future studies in systematically sampled cases would be required to resolve this issue. Assessment of cell inclusions using a reliable human specific torsin A antibody would be highly desirable. We have previously tested 4 different antibodies: torsin A [13,27,40], torsinA (TA913) [41], anti-torsin A (ab34540) and torsinA (Santacruz s-20) using western blots, IHC and immunofluorescence (unpublished data). However, none of these was found to be reliable and therefore could not be included in the study.

Despite the limitations of this study due to its retrospective nature and the restricted tissue availability our observations support the previous findings that in primary dystonia, there is no overt neurodegeneration or cell loss
[23]. The pathological change of brainstem inclusions reported in DYT1 dystonia [27] was not replicated in our case series. Hence this study supports the previous findings that overt cell loss or other obvious neuropathological defects such as inclusions do not seem to be consistently observed in DYT1 dystonia. However, subtle morphological defects of the type seen in the DYT1 mouse models (e.g. abnormalities of neuronal size/shape, dendrite structure, spines, etc.) cannot be excluded. The analogy is similar to most human mental retardation syndromes, where cell loss or inclusions are absent, but marked abnormalities of neuritic structure are thought to play an important role. The subtle morphological changes may not be identifiable using current methods. In this regard, generation of cellular disease models using the induction of pluripotent stem (iPS) cells from patient skin fibroblast has opened new horizons $[42,43]$. Understanding the cellular pathways influenced by particular mutations and the neuronal networks affected may inform future neuropathological studies.

\section{Conclusion}

We report a detailed neuropathological study of 7 DYT1 cases, the largest DYT1 case series yet investigated. The anatomical regions implicated in dystonia showed no consistent disease specific pathological features. Our observations support the previous findings that understanding the biochemical changes may be more relevant than morphological alterations in isolated dystonia.

\section{Additional file}

Additional file 1: Table S1. Semi-quantitative summary of neuronal loss (NL), gliosis pathology, Lewy bodies (LB), Tau pathology and Cerebral amyloid angiopathy (CAA) in DYT1 cases.

\section{Abbreviations}

NCls: Neuronal cytoplasmic inclusions; CERAD: Consortium to establish a registry for alzheimer's disease; NFT: Neurofibrillary tangle; IHC: Immunohistochemistry; GFAP: Glial fibrillary acidic protein; LB: Lewy body; SVD: Small vessel disease; CAA: Cerebral amyloid angiopathy.

\section{Competing interests}

The authors declare that they have no competing interests.

\section{Authors' contributions}

RP carried out genetic study, neuropatholgical study, and drafted the manuscript. AK advised on antibody optimization and provided critique of the manuscript. AL advised on immunohistochemistry staining. TL advised on western blot techniques. RB advised on antibody optimization techniques. $\mathrm{JH}$ advised on genetic studies and provided critique of the manuscript. HJ provided critique of the manuscript. KB provided critique of the manuscript. JLH reviewed the neuropathological findings and provided critique of the manuscript. All authors read and approved the final manuscript.

\section{Authors' information}

1. Research project: A. Conception, B. Organization, C. Execution;

2. Manuscript Preparation: A. Writing of the first draft, B. Review and Critique; Reema Paudel 1A, B, C, 2A

Aoife Kiely 1C, 2B 
Abi Li $1 C$

Tammaryn Lashley $1 \mathrm{C}$

Rina Bandopadhyay $1 \mathrm{C}$

John Hardy 1A, 2B

Hyder A Jinnah 2B

Kailash Bhatia 2B

Henry Houlden 1A, 2B

Janice L Holton $1 \mathrm{~A}, \mathrm{~B}, \mathrm{C}, 2 \mathrm{~B}$

\section{Acknowledgements}

We are grateful to the families and patients for their help with our research. We thank Kate Strand, Robert Courtney and Geshanthi Hondhamuni for their help with immunohistochemistry staining and antibody optimization techniques. We thank Dr Gonzalez-Alegre for his inputs in antibody optimization for this project and Robert Johnson for helping us with the tissues. We thank the NICHD, Brain and Tissue Bank for Developmental Disorder at the University of Maryland, Baltimore, MD and Queen Square Brain Bank for providing tissues.

\section{Financial disclosures}

This research was funded by grant NS 065701 to the Dystonia Coalition by the American National Institute of Neurological Disorders and Stroke and the Office of Rare Diseases Research at the National Center for Advancing Translational Sciences, Impact Studentship UCL and supported by researchers at the National Institute for Health Research University College London Hospitals Biomedical Research Centre. Dr Bandopadhyay and Dr Li are supported by Reta Lila Weston Institute for Neurological Studies. Dr Kiely is supported by the Multiple System Atrophy Trust. Dr Lashley is supported by Alzheimer's Research UK. Prof Hardy reports no financial disclosure. Prof Houlden reports no financial disclosure. Prof Jinnah is supported by grants from the NIH (NS 065701), private research foundations (Bachmann-Strauss Dystonia Parkinson's Foundation and the Benign Essential Blepharospasm Research Foundation) and clinical studies grants from industry (Ipsen Pharmaceuticals, Merz Pharmaceuticals, Psyadon Pharmaceuticals). Prof Bhatia is supported by Sobell Department of Motor Neuroscience and Movement Disorders, Institute of Neurology, UCL. Prof Holton is supported by the Reta Lila Weston Institute for Neurological Studies, the Multiple System Atrophy Trust and Parkinson's UK.

\section{Author details}

'Department of Molecular Neuroscience, UCL Institute of Neurology, London, UK. ${ }^{2}$ Queen Square Brain Bank, UCL Institute of Neurology, London, UK. ${ }^{3}$ Department of Neurology, Human Genetics, and Paediatrics, Emory University, Atlanta, Georgia 30322, USA.

\section{Received: 18 September 2014 Accepted: 25 October 2014}

\section{Published online: 18 November 2014}

\section{References}

1. Oppenheim H (1911) Uber Eine eigenartige Kramotkrankheit des Kindlichen und jugendlichen Alters (Dysbasia lordotica progressiva, Dystonia musculorum deformans). Neurologie Centralblatt.

2. Phukan J, Albanese A, Gasser T, Warner T (2011) Primary dystonia and dystonia-plus syndromes: clinical characteristics, diagnosis, and pathogenesis. Lancet Neurol 10(12):1074-1085

3. Albanese A, Bhatia K, Bressman SB, Delong MR, Fahn S, Fung VS, Hallett M, Jankovic J, Jinnah HA, Klein C, Lang AE, Mink JW, Teller JK (2013) Phenomenology and classification of dystonia: a consensus update. Mov Disord 28(7):863-873

4. Ozelius L, Kramer PL, Moskowitz CB, Kwiatkowski DJ, Brin MF, Bressman SB, Schuback DE, Falk CT, Risch N, de Leon D (1989) Human gene for torsion dystonia located on chromosome 9q32-q34. Neuron 2(5):1427-1434

5. Nutt JG, Muenter MD, Melton LJ 3rd, Aronson A, Kurland LT (1988) Epidemiology of dystonia in Rochester, Minnesota. Adv Neurol 50:361-365

6. Epidemiological Study of Dystonia in Europe (ESDE) Collaborative Group (2000) A prevalence study of primary dystonia in eight European countries. J Neurol 247(10):787-792

7. Ozelius LJ, Lubarr N, Bressman SB (2011) Milestones in dystonia. Mov Disord 26:1106-1126

8. Tarsy D, Simon DK (2006) Dystonia. New Engl J Med 355(8):818-829
9. Ozelius LJ, Bressman SB (2011) Genetic and clinical features of primary torsion dystonia. Neurobiol Dis 42(2):127-135

10. Klein C, Brin MF, de Leon D, Limborska SA, Ivanova-Smolenskaya IA, Bressman SB, Friedman A, Markova ED, Risch NJ, Breakefield XO, Ozelius L (1998) De novo mutations (GAG deletion) in the DYT1 gene in two non-Jewish patients with early-onset dystonia. Hum Mol Genet 7(7):1133-1136

11. Bressman SB, de Leon D, Brin MF, Risch N, Burke RE, Greene PE, Shale H, Fahn S (1989) Idiopathic dystonia among Ashkenazi Jews: evidence for autosomal dominant inheritance. Ann Neurol 26(5):612-620

12. Kramer PL, Heiman GA, Gasser T, Ozelius LJ, de Leon D, Brin MF, Burke RE, Hewett J, Hunt AL, Moskowitz C, Nygaard TG, Wilhelmsen C, Fahn S, Breakefield XO, Risch NJ, Bressman SB (1994) The DYT1 gene on 9q34 is responsible for most cases of early limb-onset idiopathic torsion dystonia in non-Jews. Am J Hum Genet 55(3):468-475

13. Shashidharan P, Kramer BC, Walker RH, Olanow CW, Brin MF (2000) Immunohistochemical localization and distribution of torsinA in normal human and rat brain. Brain Res 853(2):197-206

14. Konakova M, Huynh DP, Yong W, Pulst SM (2001) Cellular distribution of torsin A and torsin B in normal human brain. Arch Neurol 58(6):921-927

15. Rostasy K, Augood SJ, Hewett JW, Leung JC, Sasaki H, Ozelius LJ, Ramesh V, Standaert DG, Breakefield XO, Hedreen JC (2003) TorsinA protein and neuropathology in early onset generalized dystonia with GAG deletion. Neurobiol Dis 12(1):11-24

16. Ozelius LJ, Hewett JW, Page CE, Bressman SB, Kramer PL, Shalish C, de Leon D, Brin MF, Raymond D, Corey DP, Fahn S, Risch NJ, Buckler AJ, Gusella JF, Breakefield XO (1997) The early-onset torsion dystonia gene (DYT1) encodes an ATP-binding protein. Nat Genet 17(1):40-48

17. Granata A, Warner $\Pi$ (2010) The role of torsinA in dystonia. Eur J Neurol 17:81-87

18. Breakefield XO, Blood AJ, Li Y, Hallett M, Hanson PI, Standaert DG (2008) The pathophysiological basis of dystonias. Nat Rev Neurosci 9(3):222-234

19. Berardelli A, Rothwell JC, Hallett M, Thompson PD, Manfredi M, Marsden CD (1998) The pathophysiology of primary dystonia. Brain 121(Pt 7):1195-1212

20. Hallett M (2006) Pathophysiology of dystonia. J Neural Transm Suppl 70:485-488

21. Carbon M, Argyelan M, Habeck C, Ghilardi MF, Fitzpatrick T, Dhawan V, Pourfar M, Bressman SB, Eidelberg D (2010) Increased sensorimotor network activity in DYT1 dystonia: a functional imaging study. Brain 133(Pt 3):690-700

22. Carbon M, Ghilardi MF, Argyelan M, Dhawan V, Bressman SB, Eidelberg D (2008) Increased cerebellar activation during sequence learning in DYT1 carriers: an equiperformance study. Brain 131(Pt 1):146-154

23. Paudel R, Hardy J, Revesz T, Holton JL, Houlden H (2012) Review: genetics and neuropathology of primary pure dystonia. Neuropathol Appl Neurobiol 38(6):520-534

24. Walker RH, Brin MF, Sandu D, Good PF, Shashidharan P (2002) TorsinA immunoreactivity in brains of patients with DYT1 and non-DYT1 dystonia. Neurology 58(1):120-124

25. Furukawa Y, Hornykiewicz O, Fahn S, Kish SJ (2000) Striatal dopamine in early-onset primary torsion dystonia with the DYT1 mutation. Neurology 54(5):1193-1195

26. Augood SJ, Keller-McGandy CE, Siriani A, Hewett J, Ramesh V, Sapp E, DiFiglia M, Breakefield XO, Standaert DG (2003) Distribution and ultrastructural localization of torsinA immunoreactivity in the human brain. Brain Res 986(1-2):12-21

27. McNaught KSP, Kapustin A, Jackson T, Jengelley T-A, JnoBaptiste R, Shashidharan P, Perl DP, Pasik P, Olanow CW (2004) Brainstem pathology in DYT1 primary torsion dystonia. Ann Neurol 56:540-547

28. Granata A, Schiavo G, Warner TT (2009) TorsinA and dystonia: from nuclear envelope to synapse. J Neurochem 109(6):1596-1609

29. Shashidharan P, Sandu D, Potla U, Armata IA, Walker RH, McNaught KS, Weisz D, Sreenath T, Brin MF, Olanow CW (2005) Transgenic mouse model of early-onset DYT1 dystonia. Hum Mol Genet 14(1):125-133

30. Mirra SS, Heyman A, McKeel D, Sumi SM, Crain BJ, Brownlee LM, Vogel FS, Hughes JP, van Belle G, Berg L (1991) The Consortium to Establish a Registry for Alzheimer's Disease (CERAD). Part II. Standardization of the neuropathologic assessment of Alzheimer's disease. Neurology 41(4):479-486

31. Braak H, Braak E (1991) Neuropathological stageing of Alzheimer-related changes. Acta Neuropathol 82(4):239-259

32. Williams DR, Holton JL, Strand C, Pittman A, de Silva R, Lees AJ, Revesz T (2007) Pathological tau burden and distribution distinguishes progressive 
supranuclear palsy-parkinsonism from Richardson's syndrome. Brain 130(Pt 6):1566-1576

33. McKeith IG, Dickson DW, Lowe J, Emre M, O'Brien JT, Feldman H, Cummings J, Duda JE, Lippa C, Perry EK, Aarsland D, Arai H, Ballard CG, Boeve B, Burn DJ, Costa D, Del Ser T, Dubois B, Galasko D, Gauthier S, Goetz CG, Gomez-Tortosa E, Halliday G, Hansen LA, Hardy J, Iwatsubo T, Kalaria RN, Kaufer D, Kenny RA, Korczyn A et al (2005) Diagnosis and management of dementia with Lewy bodies: third report of the DLB consortium. Neurology 65(12):1863-1872

34. Hartmann P, Ramseier A, Gudat F, Mihatsch MJ, Polasek W (1994) Normal weight of the brain in adults in relation to age, sex, body height and weight. Pathologe 15(3):165-170

35. Den Dunnen WFA (2013) Neuropathological diagnostic considerations in hyperkinetic movement disorders. Front Neurol 4:7

36. Eidelberg D (1998) Abnormal brain networks in DYT1 dystonia. Adv Neurol 78:127-133

37. Edwards MJ, Huang Y-Z, Wood NW, Rothwell JC, Bhatia KP (2003) Different patterns of electrophysiological deficits in manifesting and non-manifesting carriers of the DYT1 gene mutation. Brain 126(Pt 9):2074-2080

38. Richter-Landsberg C, Leyk J (2013) Inclusion body formation, macroautophagy, and the role of HDAC6 in neurodegeneration. Acta Neuropathol 126(6):793-807

39. Ahmed Z, Tabrizi SJ, Li A, Houlden H, Sailer A, Lees AJ, Revesz T, Holton JL (2010) A Huntington's disease phenocopy characterized by pallido-nigroluysian degeneration with brain iron accumulation and p62-positive glial inclusions. Neuropathol Appl Neurobiol 36(6):551-557

40. Shashidharan P, Good PF, Hsu A, Perl DP, Brin MF, Olanow CW (2000) TorsinA accumulation in Lewy bodies in sporadic Parkinson's disease. Brain Res 877(2):379-381

41. Gordon KL, Gonzalez-Alegre P (2008) Consequences of the DYT1 mutation on torsinA oligomerization and degradation. Neuroscience 157(3):588-595

42. Takahashi K, Okita K, Nakagawa M, Yamanaka S (2007) Induction of pluripotent stem cells from fibroblast cultures. Nat Protoc 2(12):3081-3089

43. Yu J, Vodyanik MA, Smuga-Otto K, Antosiewicz-Bourget J, Frane JL, Tian S, Nie J, Jonsdottir GA, Ruotti V, Stewart R, Slukvin II, Thomson JA (2007) Induced pluripotent stem cell lines derived from human somatic cells. Science 318(5858):1917-1920

doi:10.1186/s40478-014-0159-x

Cite this article as: Paudel et al.: Neuropathological features of genetically confirmed DYT1 dystonia: investigating disease-specific inclusions. Acta Neuropathologica Communications 2014 2:159.

\section{Submit your next manuscript to BioMed Central and take full advantage of:}

- Convenient online submission

- Thorough peer review

- No space constraints or color figure charges

- Immediate publication on acceptance

- Inclusion in PubMed, CAS, Scopus and Google Scholar

- Research which is freely available for redistribution

Submit your manuscript at www.biomedcentral.com/submit 